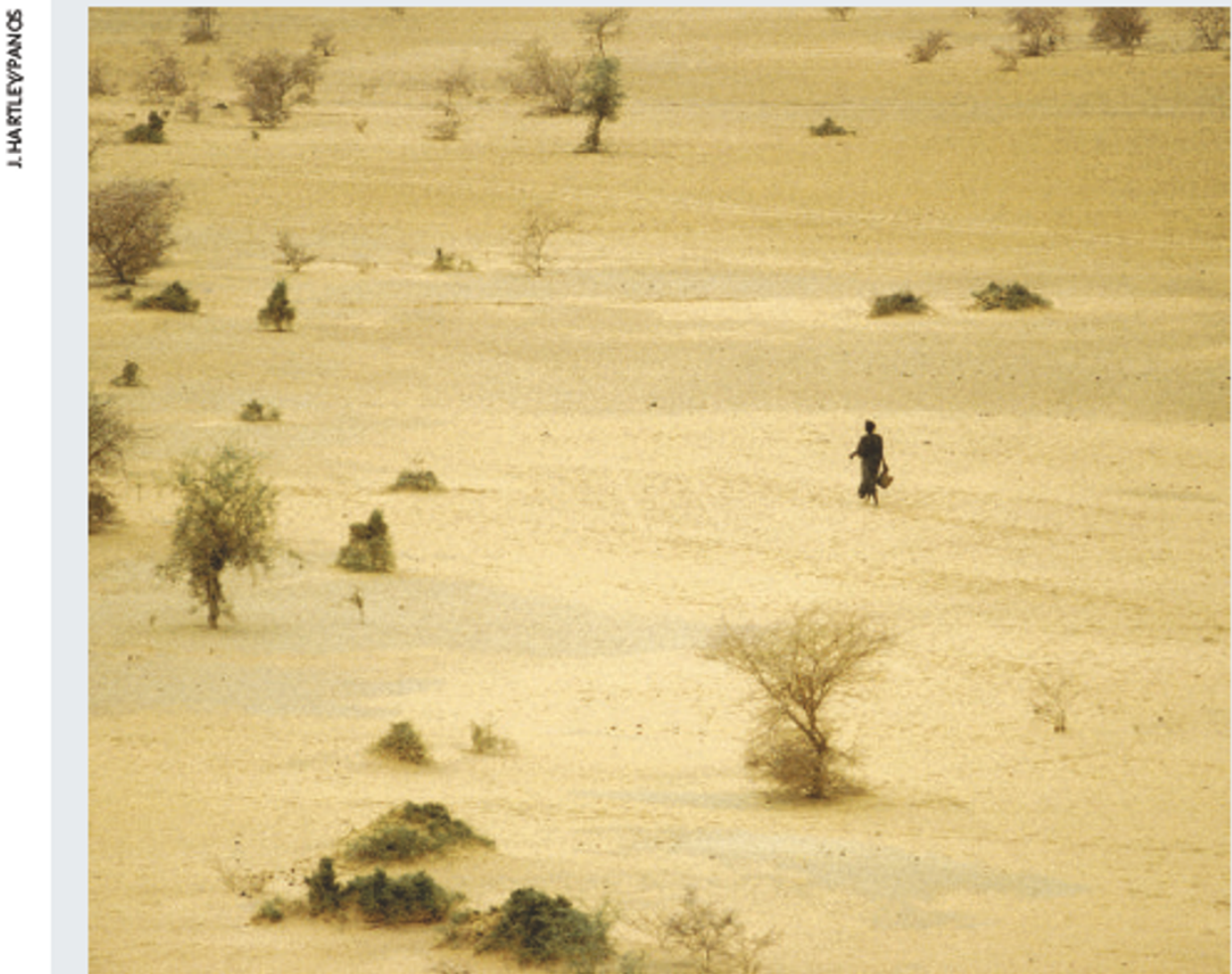

\section{Weird, sexy and mind-blowing}

The Quantum Zoo: A Tourist's Guide to the Never-Ending Universe

Marcus Chown

Joseph Henry Press: 2006. 216 pp. \$24.95

Jim Al-Khalili

This entertaining account of modern physics carries an interesting subtitle. Although I am not sure what is meant by "Never-Ending" infinite in physical extent, or in intellectual scope? - I agree with the phrase "A Tourist's Guide, as that is exactly what this book is. It is an entertaining little gem that leads the reader through many of the wonders of twentiethcentury physics with a light and sometimes quirky touch that I thoroughly enjoyed. It is so full of little insights and neat analogies that I found myself folding over the top corners of countless pages containing quotable passages. I have seen many of the descriptions and analogies elsewhere, but that is to be expected. What is remarkable is the number of new ways Marcus Chown has found to explain difficult and often abstract concepts.

The Quantum Zoo is really two books in one. The first part deals with the quantum world, whereas the second focuses on Einstein's special and general theories of relativity. The latter subject is easier to discuss at a nontechnical level, and Chown seems more relaxed once he has guided us through the counterintuitive and wacky quantum world. He stomps through quantum superposition, interference, uncertainty, tunnelling and indistinguishability with breathless enthusiasm. On consecutive pages he refers to the "weirdest manifestation of [quantum] entanglement ${ }^{\text {, }}$, the "sexiest potential use of entanglement", and the "most mind-blowing consequence of entanglement". Such superlatives carry the reader through the subatomic landscape, not always appreciating what one sees - as is inevitable with quantum mechanics - but being left in no doubt that this really is a mindblowing subject.

I preferred the second half of the book, as I felt that the author enjoys the subject matter more. Here we move to the einsteinian scale of the very fast, the very large, and curved space-time. Chown returns to the quantum only in the last two-and-a-half pages, when he touches on theories of quantum gravity.

I should give one example of the author's eye for a quirky analogy. There are many ways to describe the effects of gravitational energy, but in his playful and understated style, Chown describes the force with which a falling roof slate hits you on the head. He suggests that you measure gravitational energy via the heat generated from the impact. $\mathrm{He}$ then asks how much energy would be released were the gravitational pull of the Earth trillions of times stronger - at which point I found myself worrying more about the size of the bump on my head. Great stuff.

I could not fault the physics in either half of

\section{Thirsty work}

Nearly a billion people live in the drylands of the developing world. These often isolated mountain and desert communities spend much of their time trapping, channelling and conserving what little water there is. As a result, they are expert in one of today's urgent tasks - learning to cope with finite resources.

Dry: Life Without Water (Harvard University Press, £22.95) tells 16 stories of dryland life, from fog catching above Chile's Atacama Desert to the forest nurseries helping to regenerate Burkina Faso's nearbarren terrain (pictured). A distillation of work by the Academy of Sciences for the Developing World and the Third World Network of Scientific Organizations, these snapshots of sustainability are models of how science and traditional knowledgecan profit from each other.

The riveting images, from Massaimanaging their wetlands to vicunia shearers at work in the high Andes, underline a message that is vital at a time when drought, desertification and impending waterwars are high on the international agenda. the book, and would take issue with only a couple of points. In his description of specialrelativistic time dilation Chown describes how, if you were to travel very close to the speed of light, your time would slow down so much that the Universe's whole future would flash by in an instant. Of course, this would be true only if you were speeding up or slowing down. If you were travelling at constant velocity, you would see the opposite happen: everything outside your rocket would run in slow motion. After all, motion is, well, relative.

Chown also jumps the gun when claiming that NASA's Gravity Probe B experiment has confirmed the general-relativistic effect of space-time frame dragging by the Earth's rotation when, as far as I am aware, the data are still being analysed. I am not in any doubt that the effect will be observed and reported, probablyin the coming year, such is our confidence in the predictions of general relativity. But there is always a hint of doubt - otherwise why do the experiment?

Such quibbles aside, I hope this book does well. It is a great introduction for anyone who does not care to gain a deep understanding of the subject, or sign up to an author's pet theories, but just wants to know what all the fuss is about. This is what good popular science writing is all about.

Jim Al-Khalili is in the Department of Physics, University of Surrey, Guildford,

Surrey GU2 7XH, UK. 